Journal of Research in Interprofessional

Practice and

Education

Vol. 3.2

August, 2013
Journal of Research in Interprofessional Practice and Education (JRIPE)

Vol. 3.2

(c) 2013

Corresponding Author: Rosemary Brander. Email: 'branderr@gueensu.ca!'

\section{Using a Common Vision of Partners in Care to Enhance Hospital Collaborative Relationships}

\author{
Rosemary A. Brander, PhD, MSc, PT; Margo Paterson, PhD, MSc, \\ OT (Reg); \& Yolande E. Chan, PhD, MPhil, SM
}

\begin{abstract}
Background: Collaborative care is a philosophy that guides the work of interdisciplinary teams, patients, and their families internationally. Hospital organizations must create and cultivate environments to meet customer, health policy, and legislative mandates for improved collaborative care. This study aimed to inform and aid cultural change related to collaborative care relationships with the goal of improving the quality of care.

Methods and Findings: A critical ethnography using mixed methodologies was conducted at a mid-sized non-acute hospital in Ontario, Canada. This article presents Phase 3 of a three-phase study that engaged senior leaders (SLs) in interviews about customer service and collaborative relationships. Phase 3 findings were triangulated with prior Phase 1 study results from healthcare providers (HCPs) and Phase 2 results from mid-level leaders (MLLs). The combined findings from all three phases formed a description of the organization's culture (self-awareness, congruency, and health), explicated five organizational tensions, and generated questions and innovative change ideas to advance growth toward a shared vision of "partners in care."

Conclusions: A shared conceptual model of partners in care emerged from the shared conversations held in the research focus groups and interviews over the three phases in the study. Organizational questions, tensions, and possibilities were revealed to advance the culture of collaboration with patients, families, and staff. Innovations were identified and implemented to enhance collaborative practice.

Keywords: Organizational change; Collaborative practice; Critical ethnography; Shared leadership; Transcendent leadership
\end{abstract}

\section{Introduction}

How do contemporary healthcare philosophies, such as client-centred care or relationship-centred care, among others, become embedded in a healthcare organization's culture so that new knowledge is internalized, behaviours and norms change, and new actions become second nature? The literature demonstrates that much work is being accomplished in efforts to include and be more responsive to healthcare customers, as is evident in such areas as patient- and family-centred care [1], shared decision making [2-5], collaboration and partnership [6,7], and interprofessional practice [8]. Understanding how individuals and groups learn together within a healthcare organization so that new and vibrant cultures develop is a prevalent topic for discussion and for ongoing study [9-11].

Building profound and sustained change within organizations is dependent on changing the way people think.

In profound change there is learning. The organization doesn't just do something new, it builds capacity for doing things in a new way- 
2

Using a Common Vision of "Partners in Care"

Arnold Brander, Paterson, \& Chan

Journal of Research in Interprofessional Practice and Education

Vol. 3.2

August, 2013 for ongoing change. It is not enough to change strategies, structures and systems, unless the thinking that produced those strategies, structure and systems also changes. [12]

Leading change in an organization has been described as a collective professional responsibility, shared by all in the organization [13]. In recognition of this collective responsibility, the overall research project endeavoured to understand the views of different individuals and groups with responsibilities for clinical practice and who were employed in the healthcare organization. As is typical in many healthcare organizations, healthcare providers, mid-level and senior leaders share this responsibility. For these reasons, the research set out to understand the views of these three main groups in terms of cultivating a philosophy of collaborative care within the organization. Phase 1 focused on understanding healthcare providers' (HCPs) views about the collaborative care relationships they developed with patients and families Findings from this phase were that healthcare providers valued the relationships they developed with patients and families, and they indicated that co-worker relationships contributed to these. In addition, the healthcare providers gave much insight and discussion into ways to develop positive care relationships, barriers to developing these, and suggestions for improvements within the organization.

In Phase 2 of the research, these "change ideas" were taken to mid-level leaders (MLLs) within the organization for their perspectives and feedback. This step was taken as mid-level leaders play an essential role in communicating the stated organizational mandate and linking that with the values and sentiments of the HCPs in the organization. "Healthcare managers are responsible for threading the pieces together, organizing services, and trying to get the best value for the health resources available - in terms of both people and dollars" [14]. Middle managers construct a "person-centred workplace that deepens staff engagement" with the reciprocal result of staff promoting the well-being of the patients [15]. Because these competencies act as the foundation for building the trust necessary for success in manager/staff/patient relationships, it was important to include mid-level leader perspectives in the research. Findings from Phase 2 deepened understandings and expanded innovations for collaborative care in the organization.

Senior leaders (SLs) help to establish the vision for the work of the organization, based on governmental and hospital board mandates. Successful organizational change is a collaborative effort that requires change at all levels [16, 17]. As the goal of this study was to advance cultural change, internal workers at all levels within the organization were consulted, including senior leaders working with mid-level leaders and healthcare providers.

In Phase 3, senior leaders were interviewed regarding their perspectives on customer service and collaborative care relationships. In preparation for Phase 3, Phase 1 and 2 findings were triangulated and developed into a presentation used at the beginning of the interviews with SLs. Phase 3 results, which are presented in this article, therefore represent a cumulative summary of all phases used to build understandings of the culture of customer service and relationships for care (Table 1). 
Using a Common Vision of "Partners in Care"

Arnold Brander, Paterson, \& Chan
Journal of Research in Interprofessional Practice and Education

Vol. 3.2

August, 2013
Journal of Research in Interprofessional Practice and Education

Table 1

Study phases illustrating timelines, participants, and methods

\begin{tabular}{|c|c|c|c|c|}
\hline Phase & Preliminary & 1 & 2 & 3 \\
\hline Timelines & $\begin{array}{l}\text { Sep } 2008 \text { - } \\
\text { Mar } 2009\end{array}$ & $\begin{array}{l}\text { Apr } 2009- \\
\text { Sep } 2010\end{array}$ & $\begin{array}{l}\text { Sep } 2010 \text { - } \\
\text { Oct } 2010\end{array}$ & $\begin{array}{l}\text { Oct } 2010- \\
\text { Dec } 2010\end{array}$ \\
\hline $\begin{array}{l}\text { Participants } \\
\text { (N) }\end{array}$ & $\begin{array}{l}\text { Researcher(s) } \\
\text { (3) }\end{array}$ & $\begin{array}{l}\text { Healthcare providers } \\
\text { (10) }\end{array}$ & $\begin{array}{l}\text { Mid-level leaders } \\
\text { (13) }\end{array}$ & $\begin{array}{l}\text { Senior leaders } \\
\text { (3) }\end{array}$ \\
\hline \multirow[t]{2}{*}{ Methods } & Preparatory & $\begin{array}{l}\text { Exploratory } \\
\text { case study }\end{array}$ & Mixed methods & $\begin{array}{l}\text { Critical } \\
\text { ethnography }\end{array}$ \\
\hline & $\begin{array}{l}\text { - Literature review } \\
\text { - Grant and ethics } \\
\text { applications }\end{array}$ & $\begin{array}{l}\text { - Semi-structured } \\
\text { focus groups \& } \\
\text { interviews } \\
\text { - Observation notes }\end{array}$ & $\begin{array}{l}\text { - Survey } \\
\text { - Semi-structured } \\
\text { focus group/ } \\
\text { interview } \\
\text { - Observation notes }\end{array}$ & $\begin{array}{l}\text { - Semi-structured } \\
\text { interviews } \\
\text { - Observation notes }\end{array}$ \\
\hline
\end{tabular}

Phase 1 engaged HCPs in discussions about their beliefs and practices regarding customer service and collaborative care relationships. Their perspectives were documented and many were seen to change over time as related to an established patient- and family-centred care (PFCC) educational intervention and to related focus group discussions. Healthcare providers reported that they had new perspectives and had adopted new practices which resulted in improved collaborative care relations immediately after and up to six months following the interventions. Changes included increased awareness and acknowledgement of patients as knowledge experts, recognition of the need for patients to be fully involved and leading their care whenever able, and perceiving interdisciplinary colleagues as resource experts and as customers. Self-reported practice changes included improved communication strategies, such as enhanced listening and the use of open-ended questions, and recognizing and acting on non-verbal cues. Secondary analysis of the Phase 1 data generated themes and change ideas for the organization which were taken to mid-level leaders for further discussion in Phase 2 [18].

Following a triangulated analysis of findings from Phase 1 and 2, a summary was brought to SLs in Phase 3 to build a deeper understanding of the organizational factors that aided or hindered care relationships, with the goal of identifying opportunities for quality care. Each phase, in a stepwise approach, contributed to the ethnography through the use of focus groups, interviews, surveys, and participant observation.

The research questions that guided Phase 3 were:

- How did the senior leaders view customer service and care relationships?

- What work was occurring to enhance care relationships within the organization?

- What factors advanced or hindered the organization's care relationships?

- Which of the change ideas generated in Phase 1 and 2 may be of best use in the future, and are there others? 


\section{JRIPE}

4

Using a Common Vision of "Partners in Care"

Arnold Brander, Paterson, \& Chan

Figure 1 provides an overview of the research questions as they developed throughout the study phases.

Figure 1

\section{Study phases and research questions}

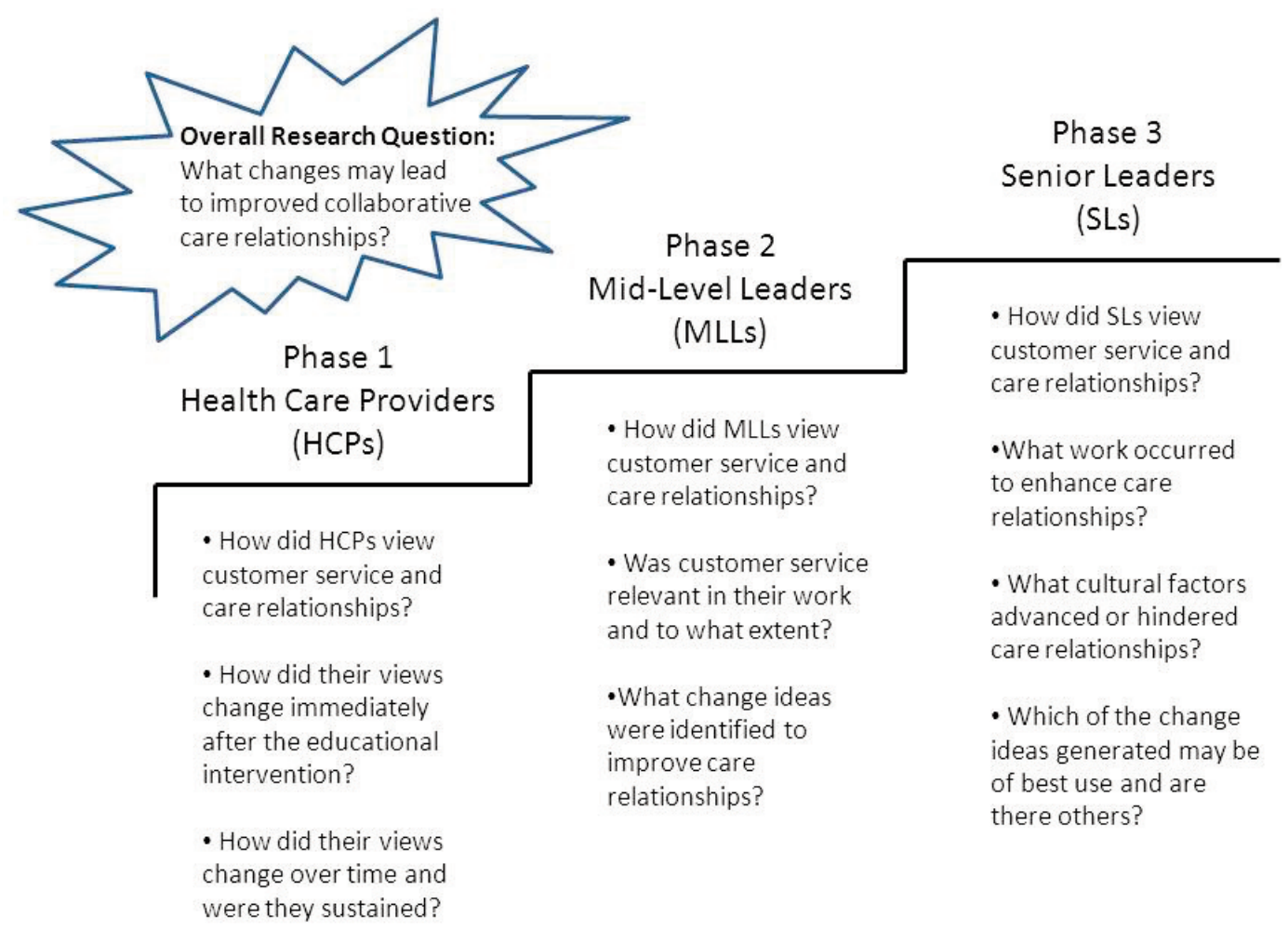

\section{Methods}

\section{Study site}

The study site for all phases was a mid-sized, multi-site, non-acute care hospital that provides inpatient, ambulatory, and community care services in Eastern Ontario, Canada. The university and the organization completed ethics review for the research. Voluntary participants received study information and signed informed consent and confidentiality agreements before enrolling.

\section{Senior leader participants and interviews}

Senior leaders who met the inclusion criteria of having formal responsibility for staff involved in clinical care and working at the research site were invited to participate. It would be these SLs who, along with their teams, would be best able to speak to describe their work with patients and families and who be in a position to apply

Journal of Research in Interprofessional Practice and Education

Vol. 3.2

August, 2013 the findings and recommendations from this research for future use. Invitations were extended to the four leaders identified who met the inclusion criteria, and three agreed to participate, forming a purposeful sample. This method of identifying inclusion criteria for a purposeful sample follows established sampling principles for qualitative research $[19,20]$. Individual interviews occurred at the 
5

Using a Common Vision of "Partners in Care"

Arnold Brander, Paterson, \& Chan

Journal of Research in Interprofessional Practice and Education

Vol. 3.2

August, 2013 participants' convenience in a private office. An interim project summary, including themes and organizational change ideas derived from prior study phases, was presented at the beginning of each interview by the first author. Following the presentation, the first author used a semi-structured interview guide to facilitate the interviews, which were audio-taped and of 1 to 1.5 hours in duration. The first author also completed an observational data form prior to and immediately following the interviews. This allowed for the collection of additional data: non-verbal cues such as facial expressions and body language, interruptions or unexpected occurrences, and time of day and environment. These notes were reviewed along with the transcriptions to provide greater insight and accuracy for interpretations during the analysis.

Transcripts were cleaned by the first author while referencing audio files for accuracy. Additional information, such as laughter, pauses, etc., was captured in memos. The analysis followed the method outlined by LeCompte and Schensul [21]. Relevant concepts were highlighted, particularly those that would link, inform, and build on concepts and themes as the analysis proceeded. New and different concepts were also identified. The frequency of concepts within the transcripts led to the development of three initial categories: changes evident, new ideas, and additional questions. The categories were used to populate a table for additional interpretation and comparison across the data. Emerging themes were noted as the data were re-coded using this taxonomy. The authors independently reviewed sample transcripts from each phase and then discussed interpretations together as the research progressed, to build consensus and trustworthiness in the analysis. As the data were jointly discussed and further analyzed, new categories were developed that better captured all of the resonating themes. The final categories used in the analysis were culture, tensions, and possibilities as related to the organization.

The critical ethnography was built in a step-wise approach using mixed methodologies over the three study phases (Table 1). A critical philosophical stance, drawing from the interpretive paradigm [22], informed the study. The research stance was related to the concept of "knowing for change," which promotes understanding about strategies to transform current structures and conditions [23]. This knowledge comes from observing the culture, by drawing cultural inferences based on what the members do (behaviours and practices), on what they make (processes and tools), and on what they say (language and shared meanings) over time [24]. The first author was immersed in the culture for two-and-a-half years while the study was conducted and also as an employee with multiple roles in the organization for over ten years.

\section{Results}

Phase 3 findings reflect an overall synthesis of the first two phases based on the senior leader perspectives. The associated themes will be discussed in the three categories of culture, tensions, and possibilities as related to the organization (Table 2) and are described below. 
6

Using a Common Vision of "Partners in Care"

Arnold Brander, Paterson, \& Chan

Journal of Research in Interprofessional Practice and Education

Vol. 3.2

August, 2013

\section{Culture}

The category of culture was derived from the representations provided by the cultural group involved with the research. Culture is defined as "the beliefs, behaviours, norms, attitudes, social arrangement and forms of expression that form a describable pattern in the lives of members of a community or institution" [25, p. 21]. For the purposes of the overall study, the broad cultural group consisted of the hospital's healthcare workers as represented by the healthcare provider, mid-level leader, and senior leader participants. The cultural themes noted below were derived with a focus on the repeated patterns and ideas that emerged through conversations and observations with the senior leaders in response to Phase 1 and 2 findings and demonstrated an organizational focus most likely due to the organizational perspectives of their work.

\section{Organizational self-awareness}

A collective organizational self-aware-

Table 2

Categories and associated themes

\begin{tabular}{|l|l|}
\hline Category & Associated themes \\
\hline Culture & $\begin{array}{l}\text { Organizational self-awareness } \\
\text { Organizational congruency } \\
\text { Organizational health }\end{array}$ \\
\hline Tensions & $\begin{array}{l}\text { Uniformity and pluralism } \\
\text { Corporatization and care } \\
\text { Liability and accountability } \\
\text { Power and leadership } \\
\text { Energy and relationships }\end{array}$ \\
\hline Possibilities & $\begin{array}{l}\text { An inquiring organization } \\
\text { An innovating organization } \\
\text { Partners in care }\end{array}$ \\
\hline
\end{tabular}

ness was described. People and groups at all levels of the organization were seen as reflecting on the critical values and actions related to their work.

[The study] gives you a good window on the internal values of the organization. The embodiment of what people think is really important, and their awareness of that within an organization. In some ways it is almost like the organization's self-awareness. (Senior leader)

The individual and group conversations, for which staff had readily volunteered, were seen as constructive processes by all senior leader participants. These discussions were used to inspire and challenge people in their efforts to understand and internalize new concepts, to adopt new belief systems, and to identify preferred practice strategies for themselves, their teams, and for the organization. In reference to the study, one leader indicated:

What you are doing, provoking the conversation ... asking the questions and not presuming the answers, is really crucial—and it's the heart of these change ideas. These are great ideas. ... We have enough [knowledge] that we can easily come back to the things we do really well and build on those, to do the next thing. I think the organization is strategically brilliant that way.... That is what you're doing, trying to help people negotiate ... what it is they do, who they are, to articulate their own sense of [purpose] and galvanize that into practical actions. (Senior leader) 
Using a Common Vision of "Partners in Care"

Arnold Brander, Paterson, \& Chan

Journal of Research in Interprofessional Practice and Education

Vol. 3.2

August, 2013

\section{Journal of Research in Interprofessional Practice and Education}

Stories that demonstrated high levels of organizational awareness were recounted. One story illustrated the way in which the organization acknowledged staff needs with groups that had been recently repatriated to other organizations. Before the move occurred, careful efforts had been made to understand what this change meant for staff, not only from an operational perspective, but also in considering staff past experiences, organizational loyalty and identity, and their needs to process and understand the change. Additional time was negotiated so that the staff successfully prepared for the change, despite pressures to move quickly. This enabled staff to participate in the planning of the change process, which culminated in a staff-led celebration. At this celebration the staff thanked the leaders and the organization for their considerable work on their behalf.

Another senior leader cited both emic and etic notoriety of the organization as being a collaborator, as opposed to a competitor, within the regional healthcare continuum. This was another indication of self-awareness and pertained to the organization's strengths.

I think there's a great spirit in the organization to move collaboration into the foreground. Our partners tell us we're really good at collaboration. ... We recognize that in order to pursue the interest of our clients, to help them get where they want to go and have a right to go, that we [need to collaborate]. (Senior leader)

\section{Organizational congruency}

Organizational congruency was defined by one participant as the match between employee perspectives and organizational actions. The comment was made in relation to the theme of "common vision" and a shared model of care derived in the earlier study phases.

The staff needs to feel like they belong in an organization where their perspective of how things should be is the perspective of how things would be. The closer the congruency between that and what is perceived by them, the more comfortable they will feel. (Senior leader)

All senior leader participants spoke about the difficulties in attempting to align different parts of the organization on one distinct and labelled model of care and indicated that this would not be a useful enterprise, and, in fact, it may undermine the goals for doing so. It was indicated that valuable models of care were already established within the organization. The feedback was that labelling one standard model for all was not as important as identifying the underlying values and principles that motivated their creation. A uniform label for the shared model of care was deemed as not important. What was seen as important was the essence of the shared values across the articulated models and to have conversations about these in order to develop organizational congruency.

There's a huge desire to come to some sort of shared model of care. ... You can look at the models and take the simplest elements, the criteria consistent with our values and beliefs. We probably need to 
Using a Common Vision of "Partners in Care"

Arnold Brander, Paterson, \& Chan

Journal of Research in Interprofessional Practice and Education

Vol. 3.2

August, 2013

\section{Journal of Research in Interprofessional Practice and Education}

have more dialogue to get past the labels. If you talk to the mental health people, they're going to talk to you about the Recovery [model], and if you really dig into that it's not a whole lot different than what we are doing [with the PFCC model]. We need to not use convenient labels as a way to obstruct others.... We need to understand what it is about the kind of care that we deliver that makes us who we are. What is it that we do that we can agree on? We all do it. It's at the heart of how we are able to do things with our clients; what we are able to do. Ask about the essence of what's behind the model. Choose the one that seems to fit most comfortably, that doesn't promote division, as models can be used as much to promote divisions within our organization as to heal them. (Senior leader)

The sense was that organizational congruency came from identifying and embracing shared values and beliefs about the work, as opposed to standardization in labels. One suggestion to represent that which was meaningful for people was the value of enhancing quality of life."

I'm reformulating the whole thing. ... How do we get together in a modern day sisterhood-a community of vision? Could we use a line from our mission statement around enhancing quality of life? That would be overarching. (Senior leader)

\section{Organizational health}

The health of the organization was raised as an issue, and differences between areas within the organization were noted. One senior leader said

my brain is always thinking, what are we doing across the two sites?

... I was happy last week as we had a joint nursing practice council between the two sites using the OTN [Ontario Telemedicine Network] ... and now we are starting to show this initiative has been changed as a result of the nursing practice council. (Senior leader)

With the view to building relationships across organizational sites, the senior leader further reflected about the use of simultaneous webcast telecommunication with the joint nursing practice council and OTN [26].

I think the use of the OTN between the two sites was powerful [during the joint nursing practice council meeting]. I was at the one site and couldn't get to the other one, but we shared. We went online and educators and community nurses [shared across sites], but no front line nurses were there. We've got to get front line nurses there. (Senior leader)

Organizational health was linked back to a need for a high degree of organizational self-awareness and congruency, with the underlying foundation for these cited as shared relationships. 
Using a Common Vision of "Partners in Care"

Arnold Brander, Paterson, \& Chan

Journal of Research in Interprofessional Practice and Education

Vol. 3.2

August, 2013

\section{Journal of Research in Interprofessional Practice and Education}

To be able to share freely and engage others ... how can one live "relationship" within Providence Care?... This [research study] gives us a bit of a window of the self-awareness that one site has about itself. I think on many levels, wow, that talks about a really healthy organization.... If we are looking at the nature of an organization, the way it relates to the world ... and its inner self workings. ... The fact that people are thinking and talking about these kind of things, isn't that great? (Senior leader)

Relationship development across all sites of the organization was a strong subtheme in all senior leader interviews. Discussions touched on all sites and services across the organization, including inpatient, outpatient, and community groups, and introspection about what could be shared, learned, and achieved using the wealth of knowledge among the groups of interprofessional staff.

\section{Tensions}

The senior leader interviews led to the realization of organizational tensions, areas in which there may be contradictions or paradoxes in the focus of the organization. These were not binary concepts but rather continuums of beliefs and opinions that can assist or hamper decisions with respect to strategic change. The five tensions that emerged were: uniformity and pluralism, corporatization and care, liability and accountability, power and leadership, and energy and relationships.

\section{Uniformity and pluralism}

Standardization is a common fixture within western healthcare. Results from such standard metrics as blood work, wait times, and bed utilization lead to many important decisions about diagnoses, prognoses, patient transfer within and across institutions, and funding. It was signaled that there may be a need to re-situate this emphasis to include interpretive philosophies and methodologies to better collaborate across disciplines, sectors, and diverse cultures in the people-centred business of healthcare.

There's the preoccupation with standardization .... but of course as soon as we standardize, it's not patient centred, it's standard centred. So there are these tensions that we live, within our society, which want to encourage and honour a more pluralistic approach to things or a standardization approach to things. Both are necessary, but we have to live in the tension of both. And I think it's the tension of both that gets people a little unsettled. (Senior leader)

An example of provincial hospital benchmarks was compared on an international level.

In Ontario, the Ontario Quality Health Council has set the benchmark for treatment in emergency room as within eight hours. Now you see these ads on TV [about American hospitals]. They are talk- 
Using a Common Vision of "Partners in Care"

Arnold Brander, Paterson, \& Chan

Journal of Research in Interprofessional Practice and Education

Vol. 3.2

August, 2013

\section{Journal of Research in Interprofessional Practice and Education}

ing about the "29-minute guarantee." If you're not seen and treated in 29 minutes, it's free. And here, across the border, we're talking about eight hours as the benchmark. What are we thinking? (Senior leader)

Although the hospital was not involved in emergency care services, this story revealed the senior leader's belief that a numeric standard in itself may not always lead the way to the desired change. In fact, it may be misleading and may even appear less than ideal when compared to other settings. Standardization and metrics without further explanation with respect to contexts, to consideration of quality of care, and to individual circumstances may misdirect or confuse the public and organizations toward less desirable goals in extremely complex healthcare environments.

\section{Corporatization and care}

A continuum of tension between the allocation of resources and the provision of care was revealed. This tension was noted by healthcare providers in earlier study phases, often with the view that the two poles of the continuum were mutually exclusive. The senior leader data displayed their increased efforts to involve healthcare providers in setting corporate targets for care. One example given was the dialogue that occurred with the Quality Teams around hand hygiene compliance. The Quality Teams are composed of a majority of healthcare provider and mid-level leader members, and they report directly to the corporate committee of Quality, Safety, and Risk within the hospital.

For our hand-washing compliance the ultimate goal is 100 percent. When we started we were at 56 percent and our last quarter was 80 percent. Now where do we go with the target? So we took the conversation to the Quality Teams as to where does the [next] target get set? And having that conversation is part of how that goal will change. We wouldn't have done that two years ago. (Senior leader)

The indication was that the organization had changed. It was now involving those closest to the work, those providing the care, to establish reasonable target metrics and goals.

There were other examples given where the allocation of resources and provision of care were not as well synchronized, and these were identified as requiring change.

There's been a program that's been sidelined for at least a year which helps people to learn how to cook for themselves. We are trying to discharge long-term clients and they don't know how to cook anything for themselves. Nobody seems particularly worried that the only facility they have to learn this in has been out of commission for a year. That's just crazy. (Senior leader)

In this example, a provision of care issue, discharge, is not being well supported due to the fact that the facilities, which allow for adequate preparation for discharge, 
11

Using a Common Vision of "Partners in Care"

Arnold Brander, Paterson, \& Chan

Journal of Research in Interprofessional Practice and Education

Vol. 3.2

August, 2013 were not available. Details regarding the delay were not explained, but somehow the resources were not available to meet the discharge goal.

\section{Liability and accountability}

A third tension was that between the concern for liability and open accountability. The example provided was about the freedom of access to the patient record, "the chart." Legally the chart is the patient's information and the patient has the right to access it, but this is not so easily translated into practice. Patients typically do not lift the chart off the shelf at the nursing station and open it up and read it whenever they so wish. Sophisticated access procedures include formal requests to the patient records departments, permissions from the admitting physician(s), and/or requiring an employee observer to be present while the patient's record is being accessed by the patient. One senior leader contrasted these typical inpatient record practices with those used in community service areas within the organization.

For about 3,000 of our clients, the chart is on the fridge ${ }^{1}$. When I hear people talking about patient confidentiality, I think to myself, well excuse me, but the chart is on the fridge. [Said with emphasis.] It's kind of laughable when you realize that that's how we communicate with many [of our community partners]. (Senior leader)

The above example clearly reveals differences in access to patient record information in inpatient versus community patient areas. The question then arises as to why the concern for liability and open accountability are different in these two areas.

One of the change ideas presented in a prior study phase was to "chart as though the patient will read the chart." Concerns about liability were conflicted with a desire for openness and improved communication with patients. The chart exemplifies this conflict. The complexity of this issue was reflected in one senior leader's suggestion: "We should do a study to have patients read the file to see what impression they get." The discussion following this comment was that description of an occurrence in the patient record by the HCP might be a very different representation from the understanding of the patient. Another suggestion by a SL was that "We should give patients access to the file on a regular basis, say every Thursday is read your chart day." Perhaps if patients reading the patient chart on a weekly basis became a standard by which we would work, collaboration in care would improve. It was also suggested that formal research and external rules were needed in these areas because the traditional norms were anticipated to act as constraints.

Complexity was also reflected in comments about patient fears of staff repercussions, and about staff fears of patient complaints, when a patient asks to read the chart. Layered on top of these complexities were embedded views and confusion about legal and other constraining processes. For example, it was not clear if the organization was required to "maintain privacy of third party information" (i.e., patient information documented by other hospitals) by removing that information from the chart before extending it for patient access. The question was raised, "If patients read their files on a regular basis, would we be as fearful, or would we actu- 
Using a Common Vision of "Partners in Care"

Arnold Brander, Paterson, \& Chan

Journal of Research in Interprofessional Practice and Education

Vol. 3.2

August, 2013

\section{Journal of Research in Interprofessional Practice and Education}

ally change our charting practices?" Senior leaders suggested that improving patients' access to their charts would result in improved documentation and decreased fear and stigma among hospital staff. This tension represents an opportunity for improved communication and accountability and a move away from a focus on liability.

\section{Power and leadership}

Attention to the language used by the participants provided insight into the organizational culture with respect to power relationships. One senior leader noted the use of the verb allow in the change idea "allow teams enough time for strategies to come forward" and again in "allowing the patient to read the chart." A senior leader asked the question, "What is the use of authority?" This flagged a common tension between authority and control. Similar verbs that inferred permission or the conferring of power from one deemed as having power to another with lesser power were seen throughout all study phases.

One of the senior leaders spoke about the importance of the manager role as a positive role model with regard to the change idea "create a culture of peer-to-peer mentorship." Those with power were traditionally seen to be those in positions of authority: managers with respect to staff, or physicians and healthcare providers with respect to patients.

I believe that the role of the manager is really crucial in being a person to bring [power imbalances] forward in conversations ... when you get together as a group [the manager] sets the tone and how you interact one-on-one with people sets the tone. (Senior leader)

Within this tension there existed an underlying theme regarding the value of mentorship. A question was asked about the extent to which leaders play a role in productive mentorships, and one senior leader responded:

People who were powerful mentors for me were not chosen by an organization, or by a particular system of selection-except my own. I knew it. You just know it in yourself-this is a person that I could learn a lot from ... Mentoring happens. It's not formal. (Senior leader)

Practice councils had been developed within the organization in the previous five years to assist with community-of-practice decision making. Practice councils are composed of like-discipline clinical staff members and have the goal of supporting clinical best practice and assisting members and the organization in understanding and enacting these practices for quality patient care. The recent formation of the Joint Nursing Practice Council, a new venture of practice councils working together between two organizational sites, furnished evidence of excellent staff leadership.

Last week we had a Joint Nursing Practice Council meeting. ... One group was amazing. The front line nurses articulated how they were having an impact on the practice through the practice council. 
Using a Common Vision of "Partners in Care"

Arnold Brander, Paterson, \& Chan

Journal of Research in Interprofessional Practice and Education

Vol. 3.2

August, 2013

\section{Journal of Research in Interprofessional Practice and Education}

Information comes from the nurse on the unit and to Council and they're now starting to advertise examples of "this initiative has been changed as a result of Nursing Practice Council." ... I had an epiphany, which I shared later with the group. I said to them, "Anything that comes from Nursing Practice Council, I never get my back up." I say, "Okay tell me what's going on, tell me what you're thinking. How did you come to this? Who was consulted? How do we move on this?" ... When it comes to this group ... I pay full attention. (Senior leader)

Excellence in practice was seen to be the Council's prime motive, and this shared focus engendered opportunities for shared leadership - a balance of power with respect to leadership within the organization.

\section{Energy and relationships}

The balance between negativity and positivity in the environment was characterized by a senior leader participant as energy flow. It was stated that there were often persons in an organization who brought a negative perspective in their comments and contributions. It was recognized that it was difficult for leaders to know how much time to invest in addressing these negative perspectives.

If someone is really negative and you engage them, they draw that energy from you, so you are actually feeding it. Whereas if you just acknowledge them and not be available for them to take your energy, after a while they burn themselves out. ... We are generally a pathology-preoccupied culture, and so we see that as being the problem and we put all sort of energies on it. But are we actually feeding it? Energies that could have gone to other people who are just a bit anemic but still healthy [are used]; let's put our energies there. (Senior leader)

A focus on the quality of relationships organization-wide, with attention to that which already exists that is healthy and positive, was felt to lead to an improved environment.

The more we open our relationships to patient and families the more we will be patient and family centred in our care... To me it's from dimensions of human existence that connect from our heart, from empathy or some kind of greater connectivity, or the quality of the relationship [as to how we will reach this goal]. (Senior leader)

Building on the perspectives of the healthcare providers and mid-level leaders in turn gave strength to the shared organizational values related to patient-centred care. The senior leaders' vision was expressed to include a broader view for relationship-centred care, to depict mutuality and equality and an awareness of self that is necessary for relationships. 
Using a Common Vision of "Partners in Care"

Arnold Brander, Paterson, \& Chan

I think it is great to move toward patient-centred care because that's a big step over some of the previous paradigms. But I think relationship-centred care is even more important, as then one must be aware of oneself within the relationships ... rather than what I'm going to do to, or for, or at, the patient-which can be an unconscious outcome of the patient-centred care (model). I don't think that is the intent; however, there is that possibility. (Senior leader)

This view concurred with conclusions drawn in previous study phases. Participants indicated that their relationships with colleagues would affect their relationships and work with patients. In considering relationships and models of care,

how we work together actually improves our level of care for patients. How we communicate with each other, report time or change of shifts, hand off all of those things that we are working on, impacts our whole experience of working with our patients and their families. (Senior leader)

\section{Possibilities}

\section{An inquiring organization}

Senior leader participants asked a combined total of over 70 questions during 3.5 hours of interviews. These questions were related to the organization, the work and the staff, and the patients and families, which it serves. A sample of the questions is presented and aligned with the previously defined cultural themes of organizational self-awareness, congruency, and health (Table 3 ). These questions are representative of the degree to which the senior leaders are reflecting and contributing to a culture of inquiry and openness to new ideas within the organization.

\section{An innovating organization}

Many innovative change ideas evolved as the participants explored similar questions; shared their knowledge, opinions, and experiences; and constructed mental models. Some of these change ideas have been shared previously [18] and will be used to stimulate further discourse, debate, and action within the hospital.

Phase 1 resulted in the identification of five themes from the healthcare providers' perspectives as related to the patient- and family-centred education and focus group interventions overtime. These were: customer, customer service, knowledge, roles and, common vision. Phase 2 revealed additional themes based on midlevel leaders' perspectives of customer service and care relationships within the organization and in response to a summary of Phase 1 findings. These were: being

Journal of Research in Interprofessional Practice and Education

Vol. 3.2

August, 2013 present, communicating well, taking action, having and recognizing each other's expertise, and collaborating. From the triangulation of all three study phases, six overall themes emerged as important for the development and achievement of collaborative care relationships within the organization. The first three of these had been identified in Phase 2, but the verb tense was changed for brevity, with no intent 


\section{JRIPE}

15

Using a Common Vision of "Partners in Care"

Arnold Brander, Paterson, \& Chan

Journal of Research in Interprofessional Practice and Education

Vol. 3.2

August, 2013
Table 3

\section{Questions aligned with organizational self-awareness, congruency, and health}

\begin{tabular}{|c|c|}
\hline Cultural themes & Sample questions \\
\hline $\begin{array}{l}\text { Organizational } \\
\text { self awareness }\end{array}$ & $\begin{array}{l}\text { - How can we live relationships at Providence Care? } \\
\text { - How do we communicate that our relationships with each other impact our work with } \\
\text { our patients and families? } \\
\text { - How do we pay attention to the things that aren't working? } \\
\text { - How do we improve the quality of what we have, without doing that in a way that } \\
\text { operates as a critique? }\end{array}$ \\
\hline $\begin{array}{l}\text { Organizational } \\
\text { congruency }\end{array}$ & $\begin{array}{l}\text {-What are the consistencies across the models [of care] already in place across the } \\
\text { organization? } \\
\text { - How do we capitalize on the value of what we have as an organization and bring that } \\
\text { together [across sites and groups]? } \\
\text { - How do we put the question in a way that will help people come together? } \\
\text { - How does it get internalized to our day-to-day lives? }\end{array}$ \\
\hline $\begin{array}{l}\text { Organizational } \\
\text { health }\end{array}$ & $\begin{array}{l}\text {-What are we thinking when we're talking about benchmarks? Where do we set the } \\
\text { target, e.g., hand-washing compliance? } \\
\text {-What does the information from the quality teams really mean? What is that telling us } \\
\text { about our clients? } \\
\text {-We have excellent patient satisfaction results. How do we make sure that our staff are } \\
\text { feeling the same way? } \\
\text {-What are the questions that we want to ask [in satisfaction questionnaires]? } \\
\text {-Which questionnaires and validated questions should we use? How do we improve the } \\
\text { quality and validity of the questions? } \\
\text { - How do we use the information? What have we done with it year after year? } \\
\text { - Some policies and procedures look great, but do they work? } \\
\text {-What is the object of the process? } \\
\text {-When is it that people are indoctrinated early on in the Western model as to what } \\
\text { success is or means? } \\
\text {-When does the preoccupation with measurement actually push us past the threshold of } \\
\text { that which is helpful? }\end{array}$ \\
\hline
\end{tabular}

to change the meaning. These were: be present, communicate well, and collaborate. The three new themes added were: model the way, be open to new ways, and make sufficient time. The new themes are discussed below and details of the first three themes have been discussed previously.

Model the way is composed of two subthemes: leadership and mentoring. These subthemes were evident across all study phases but were strongly represented in the senior leader conversations. Senior leaders recognized the significant contributions of mid-level leaders in providing leadership in formal work relationships with their teams. Self-selected mentorship and learning was also suggested as another important consideration in contributing to organizational culture. 
Using a Common Vision of "Partners in Care"

Arnold Brander, Paterson, \& Chan

Journal of Research in Interprofessional Practice and Education

Vol. 3.2

August, 2013

\section{Journal of Research in Interprofessional Practice and Education}

Some cultures say, "when I'm ready to learn, the teacher appears." That's important for us. When we think of how professional development of healthcare staff is supported and enabled, it's through relationships. People who were powerful mentors for me were not chosen by an organization or by a particular system of selectionexcept my own. (Senior leader)

The fifth theme, be open to new ways, includes subthemes of acknowledgement (which included concepts of ownership and accountability) and the need to be aware of old ways. A staff member suggested that acknowledgement included concepts of ownership and accountability during onefocus group. The term acknowledgement appealed to the staff attending the same focus group as it connected the reasons for taking ownership and being accountable with that of acknowledging the importance of these skills to build mutual trust in relationships.

One senior leader underscored the importance of acknowledgement, ownership, and accountability:

I think you need to be willing to have the patient look you in the eye and say, "Are you really saying that about me?" So I think, "chart as if the patient will read the chart" is great accountability. (Senior leader)

An awareness of old ways was reflected as important by one senior leader "because we are always looking for something new and we may already have something that works well." On the other hand, an awareness of old ways was expressed as necessary to direct the organization to new perspectives for care. The example was given of the organization's role of providing a home and care for long-term patients, some for over 25 years.

There was no opportunity to think about any [other form of care]. So now we're trying to learn lessons about how one can [isolate] someone by taking great care of them, protect them from the world so that they have no opportunity to participate. (Senior leader)

By understanding history and old ways, new understandings and ideas may evolve.

It seems no study of culture, particularly healthcare culture, can exclude the concept of time. Make sufficient time was the sixth theme and was portrayed as essential for the development of relationships. This theme was prevalent throughout all study phases and was seen as a significant facilitator for relationships in a humancentred organization, as stated by one senior leader:

There is this element of time that engages complexity to engage the person. If we are dealing with complex situations and not allowing the team to move to the dimension of personal space and team space to engage complexity, they are always simplistic [conversations]. It never gets us anywhere and continues to build the moral distress that people feel. (Senior leader) 
Using a Common Vision of "Partners in Care"

Arnold Brander, Paterson, \& Chan

Journal of Research in Interprofessional Practice and Education

Vol. 3.2

August, 2013

\section{Journal of Research in Interprofessional Practice and Education}

Time was also discussed from the perspective of improving service for the patient and family. An example of making time on their behalf was the reduction of waiting time for a first appointment from 12 weeks to less than 3 weeks; a $60 \%$ reduction was achieved by examining the existing intake process and identifying opportunities for change. Details of the project were not related in the interview, but there was a focus was on "don't waste the patient's time; don't waste the family's time." The senior leader related another change initiative that had resulted in a faster admission time for a patient.

We believe there are plenty of opportunities to [make better use of time]. Why did it take us three weeks to take a referral? We recently had one from a rural area. The doctor went up there and looked at the patient. He came back and re-admitted the patient. Period. He knew when he saw this patient that this was a tertiary care patient [who required admission]. In terms of process, that's pretty efficient. I think this is an enormously helpful notion: How do we understand what we need to do with this client and family right away? How do we not waste their time? (Senior leader)

\section{Partners in care}

Senior leaders portrayed a ready understanding of the application of customer service in the workplace, as had the mid-level leaders in Phase 2. One senior leader anticipated the tensions related to the use of customer service terminology, in reference to corporatization and care.

Customers comes from the language of business and business interaction and ensuring you give the customer what they want to consume. As a customer, I'm going to get what I want, which is very unique to me.... It touches on a real tension within healthcare in Canada right now around corporatization, the move to healthcare that is more [based on] consumption and run by a business mentality. There is a real tension between those who have a different worldview around care as opposed to consumption. (Senior leader)

The recurrent themes, carried through all study phases, were used to create the formative conceptual model in Figure 2. A strong thriving plant was chosen to represent the dynamic and complex hospital organization, supple and malleable and responsive to its environment. The top centre of the figure is labelled "Partners in Care," the shared vision that was identified as building consensus for collaborative care relationships. At the bottom of the figure are the roots which represent values portrayed within the organization's mission statement, "Strengthening our Relationships," "Enhancing Quality of Life," and "Compassion.” Extending toward and away from the centre of the plant are strong leaves that symbolize the six themes which incorporate the components necessary for success in care relationships: to be present, communicate well, collaborate, model the way, be open to new ways, and make sufficient time. 


\section{JRIPE}

18

Using a Common Vision of "Partners in Care"

Arnold Brander, Paterson, \& Chan
Journal of Research in Interprofessional Practice and Education

\section{Discussion}

The final research phase helped to situate the previous study findings into a broader understanding of the culture of collaborative care relationships and the interplay between individuals and groups working in different roles and levels within the organization. Through focused discussions, healthcare provider participants developed a shared vision and generated change ideas that in turn were explored by midlevel leaders and lastly, by senior leaders. The resulting picture was that of a dynamic organization responding to change at all levels to meet both internal and external mandates for increased collaboration with patients and families. Through

Figure 2

\section{Conceptual model for collaborative care relationships within the organization}

\section{Partners in Care}

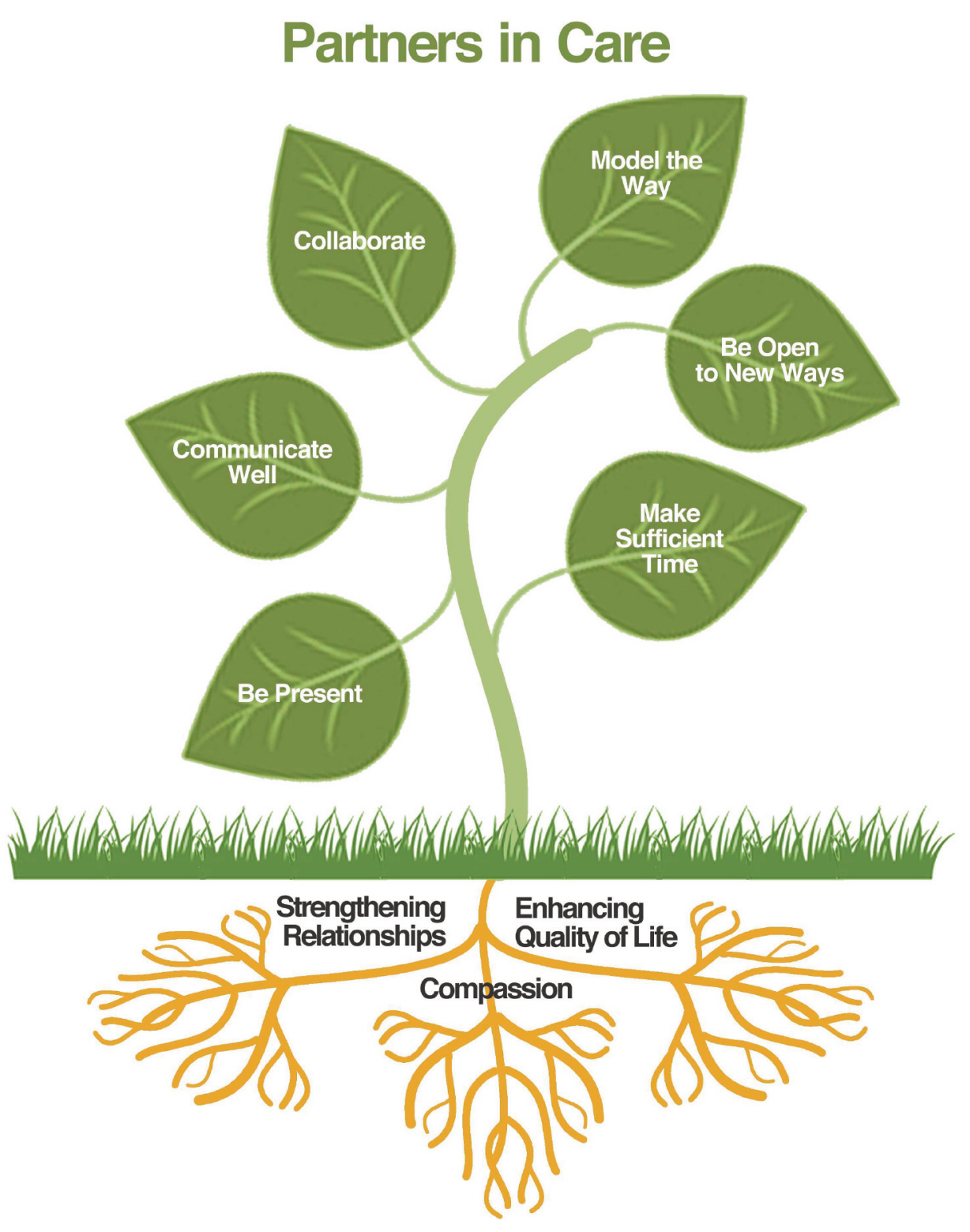

Journal of Research in Interprofessional Practice and Education

Vol. 3.2

August, 2013 'www. 
19

Using a Common Vision of "Partners in Care"

Arnold Brander, Paterson, \& Chan

Journal of Research in Interprofessional Practice and Education

Vol. 3.2

August, 2013 the research, participants recognized that enhanced relationships with interprofessional co-workers from similar and different disciplines, backgrounds, and roles would also contribute to the goal of enhanced relationships with patients and families. The organizational culture will be discussed from the perspectives of values, learning, leadership, and innovation.

\section{Culture and values}

Although the senior leader participants readily identified with the term customer service, Phase 1 demonstrated that this was not the preferred vision on which to build work relationships with all stakeholders. Preferred representations included partners in care, patient- (and family-) centred care, and relationship-centred care, as presented previously [18]. Differences in patient groups, histories, and structures had led to the use of a variety of models of care. Senior leader participants recognized that it was most important to emphasize the common values and principles of these models in order to build positive relationships with and among all stakeholders, rather than to identify one specific model as fitting all sites and groups. This agrees with a growing body of research, which indicates that the purpose, vision, and values communicated within a hospital mission statement are positively related to organizational performance $[27,28]$, and through shared values and beliefs, people are empowered to act in accord with the organizational directions.

Values function as the mortar of organizational life by cementing the foundation of vision and purpose ... Values also become magnets, attracting and building loyalty among individuals who share and honor the same ethos ... belonging to a group with high-minded values, employees know that they are working with splendid purpose for a hospital with greatness in its sights [27].

\section{Culture and learning}

An interdisciplinary education initiative, similar to the educational intervention used in our study in that it was based on the best practice guideline for client-centred care [29], was shown to influence the spread of values related to client-centred practice within another hospital organization [30]. Key goals of the Ford et al. project were to build consensus and support for the best practice guideline regarding client centred practice. The Ford et al (2001) research demonstrated results of consensus and support for client centred care by documenting a number of hospitalwide initiatives which had been implemented.

Our research reflects some similar outcomes and spread to that of Ford, et al (2001), which can be attributed in part to the PFCC educational intervention, also based on the RNAO practice guideline. One strong indicator of the value of the education to the organization was that PFCC educational intervention was re-initiated in January 2012, after a 1.5-year hiatus, in part due to feedback from the participants and early research results. The new education has been opened to all disciplines from any of the organization's sites, reflecting increased efforts for interdisciplinary and cross-site collaboration. Other new initiatives which have 
20

Using a Common Vision of "Partners in Care"

Arnold Brander, Paterson, \& Chan

Journal of Research in Interprofessional Practice and Education

Vol. 3.2

August, 2013 been developed include the publication and discussion of patient satisfaction results in hospital newsletters and at open staff forums, to heighten awareness of opportunities for improvements in care. One of the hospital programs chose patient autonomy as a quality improvement initiative in 2011-2012. Improved communications across the organization were evident in the use of electronic newsletters, which showcased staff-contributed success stories and celebrations.

Highly innovative and adaptive organizations close the gaps between espoused organizational values and actual practice [31]. Practice is created and enacted within communities of practice by employees who learn and problem-solve together in order to succeed in their work. Organizations that close this gap possess leadership that promotes working, learning, and innovating as interrelated, compatible, and necessary. The willingness of individuals and groups within an organization to co-operate and share knowledge is a critical dimension for knowledge transfer [32]. This study portrayed participants learning "from, with and about" each other, defined as foundational for interprofessional education, individually and in groups and across organizational levels [33]. It has demonstrated that learning, steeped in the values and vision of the organization, can have influence beyond what was initially planned.

\section{Culture and leadership}

Ideal leaders have a strong influence on organizational culture, building trust by modeling excellent relationship skills and by encouraging collaboration and knowledge transfer. Two theories of leadership will be discussed as related to the study: shared leadership and transcendent leadership.

Shared leadership is conceptualized as leadership that is distributed among members within an organization [34]. It is defined as "the ongoing, mutual influence process through which leadership is rotated to the person with the key knowledge, skills, and abilities for the particular issues facing the team" and is inherently part of the organizational system [35, p. 573]. Depending on situational needs, leaders come forward and then step back when no longer needed. Shared leadership intuitively links to communities of practice engaged in problem solving and in making sense of their environment to improve their work. Leaders may be formally designated within teams, but they also can be members who may step up to facilitate team and administrative processes. This form of leadership banks on the unique strengths of individuals as a resource for the organization. Providing learning opportunities, such as PFCC education, and collaborative research opportunities, such as demonstrated in this study, developed unique skills within individuals and groups aligned with the strategic directions of the organization. These learning and research models encouraged leadership to be distributed among many members of the team. In future it is hoped that the organization will continue to mentor and facilitate new opportunities for leadership that includes non-traditional leaders and roles, such as the patient and family, educators, and researchers working in tandem toward the organization's goals.

A shared leadership model links with the theme collaborate found in this study. It incorporates the value of mutual respect and acknowledges the need for a variety 
21

Using a Common Vision of "Partners in Care"

Arnold Brander, Paterson, \& Chan

Journal of Research in Interprofessional Practice and Education

Vol. 3.2

August, 2013 of knowledge areas and expertise to meet and lead a variety of situations. Collaboration facilitates models of shared leadership as it allows for differentiation of roles and influence so that informal leaders may emerge.

Crossan, Vera, and Nanjad [35] propose transcendent leadership as a framework that represents the responsibilities necessary for strategic leaders to be successful in rapidly changing environments, such as in hospitals [36]. This framework requires the leader to lead self, others, and the organization and indicates that all three components are interdependent and necessary for optimum organizational performance. Within individual, group, and organizational levels a learning perspective must thrive in order to be responsive to the rapidly changing environment. "The strategic leader's responsibility is to provide the infrastructure that enables learning to flow throughout the organization" and to help to create and sustain value-based visions for the organization that are grounded in principles for high capabilities and not in rigidities [35]. The focus is on what is to be accomplished and less on the details of how it is done. Management is oriented toward entrepreneurship and coaching to build environments of trust and purpose and less focused on controlling and implementing.

One can readily envision an organization in which these two types of leadership are interdependent. The transcendent leader models and enables the vision and directions for the organization while encouraging shared leadership among others who are engaged at the interface of the work, such as those engaged in patient care in a hospital. Crossan et al. [35] indicate that this diffusion of leadership throughout the organization strives for a balance of freedom and structure that encourages exploration and innovation.

\section{Culture and innovation}

Many of the components of the partners-in-care conceptual model coincide with that described as necessary for complex evolving and responsive organizations, which adapt and thrive on change [28]. Youngblood describes three necessary components as shared vision, personal leadership, and free flow of information, all of which are described in this study. Many of the change ideas created also echoed themes outlined by Youngblood and others. These components lead to innovation, in part where an organization actively constructs a conceptual framework, imposes it on the environment, and reflects on the interactions and outcomes [31]. By adopting new learning models with PFCC and by encouraging staff participation, active reflection, and opportunities to practice and self-reflect, the organization has built and strengthened its innovation in collaborative care relationships.

\section{Limitations, relevance, and future research}

Phase 3 was limited to the senior leaders who met inclusion criteria and volunteered for the study; however, not all senior leader roles were represented. For example, it would have been useful to have had a physician senior leader participate. As well, the information presented to the senior leaders from the prior two phases reflected the self-reported knowledge from volunteer healthcare providers and mid- 
22

Using a Common Vision of "Partners in Care"

Arnold Brander, Paterson, \& Chan

Journal of Research in Interprofessional Practice and Education

Vol. 3.2

August, 2013 level leaders from one site of the multi-site hospital. A greater variety of disciplines, across all organizational sites, would have provided more varied data, but this was not within the scope of the study. Additional participant observation would also have enriched the data, but this is not always easy in healthcare environments due to such limitations as space and privacy. There remains the challenge of shifting perspectives as culture evolves in a complex hospital organization, and it is necessary to reflect on those whose voices may not have been heard [22]. The sequential progression of the study allowed for consultation of participants representing different roles and within levels, but in future it would be of interest to consult with groups across organizational levels to build greater consensus and understandings.

Ethnographic findings typically are specific to the local culture; however, many of the findings in this study appear to have wider relevance. Interprofessional collaboration has been defined as "the process of developing and maintaining effective interprofessional working relationships with learners/practitioners, patients/ clients/families and communities that enable optimal health outcomes" [37]. In this collaborative of experts, interprofessional communication and patient-/client-/ family-/community-centred care were determined to be foundational competencies that supported and influenced the remaining four domains of role clarification, team functioning, collaborative leadership, and interprofessional conflict resolution. The findings in this study echoed competencies of collaboration and communication that were generated by a focus on patient-centred care education.

The World Health Organization (WHO) (2010) in its "Framework for Action on Interprofessional Education \& Collaborative Practice" [38] also cites communications strategies as one of the working culture mechanisms that shape collaborative practice. It notes that institutional supports, such as clear governance models, supportive management practices, and adequate time for interprofessional collaboration, contribute to successful collaborative practice. This study generated a shared vision for the work among participants with varied staff levels, roles, and disciplines and generated many questions and innovations related to collaboration. Making sufficient time was a theme found in the study that was similar to that determined in the WHO framework. The conceptual model of partners in care was found to echo values within the organization's governance mandate and strategic directions, which aligned with the WHO institutional mechanisms for collaborative practice.

In "Assessing Initiatives to Transform Healthcare Systems: Lessons for the Canadian Healthcare System" [39], two of six themes defined as crucial for healthcare transformation are creating an enabling environment and patient engagement. Creating an enabling environment involved using effective governance models and engaging professionals with the acquisition of new competencies and skills by managers and providers alike. In this study, shared conversations and findings about collaboration culminated in innovative change ideas, many of which included ways to enhance patient engagement in the organization.

The study adds to foundational knowledge of a hospital organization undergoing innovation as it works toward collaborative care relationships with staff, patients, and families. Patient- and family-centred care education, along with 
Using a Common Vision of "Partners in Care"

Arnold Brander, Paterson, \& Chan

Journal of Research in Interprofessional Practice and Education

Vol. 3.2

August, 2013 guided conversations in focus groups, interviews, and meetings, revealed a variety of opinions and created a shared vision for care. The critical ethnography presented an interpretation of the findings that contributed to the conceptual model of partners in care and generated many innovative change ideas from participants across all organizational levels. The findings are being used for further organizational development: for example, they are currently being used in PFCC education sessions to stimulate and nurture the conversations. Next steps will be to consult with groups and leaders about the innovative change ideas, some of which have already been implemented within the organization. Further research will help to identify which of the innovations have improved collaborations across teams that include the patient and family.

\section{Conclusions}

The critical ethnography depicts a healthcare organization undergoing renewal. Cultural themes emphasized existing strengths of an inquiring organization as it develops a community of vision for collaborative care with a view to a relationshipcentred governance model at individual, group, and institutional levels. Organizational questions, tensions, and possibilities were explicated for future shared conversations and debate in directing the organization toward its goals for enhanced quality of life for its customers, patients, families, and staff.

\section{Abbreviations}

HCPs Healthcare providers

MLLs Mid-level leaders

PFCC patient and family centred care

SLs Senior leaders

WHO World Health Organization

\section{Notes}

1. For the purposes of this study, the phrase relationships for care is used broadly to include the relationships formed among healthcare co-workers (interprofessional, interdisciplinary, and those with different and/or similar roles and backgrounds) and between healthcare workers and patients (and their families). Collaborative care relationships and care relationships are phrases used synonymously with relationships for care in this article.

2 . The reference to 3000 charts was figurative indicating that many community dwelling patients maintain current records and clinical advice on their home fridge.

\section{References}

1. MacKean, G.L., Thurston W.E., \& Scott, C.M. (2005, March). Bridging the divide between families and health professionals' perspectives on family-centred care. Health Expect, 8(1), 74-85.

2. Weston, W.W. (2001). Informed and shared decision-making: The crux of patient centred care. Canadian Medical Association Journal, 165, 438-440.

3. Légaré, F., Stacey, D., Graham, I., Elwyn, G., Pluye, P., Gagnon, M-P, Frosch, D., Harrison, M.B., Kryworuchoko, J., Pouliot, S., \& Deroches, S. (2008). Advancing theories, models and measurement for an interprofessional approach to shared decision making in primary care: A study protocol. BMC Health Services Research, 8(1), 2.

4. Légaré, F., Stacey, D., Pouliot S, Gauvin F-P, Desroches S, Kryworuchko J, et al. (2011). Interprofessionalism and shared decision-making in primary care: A stepwise approach towards a new model. Journal of Interprofessional Care, 25, 18-25. 
Using a Common Vision of "Partners in Care"

Arnold Brander, Paterson, \& Chan

Journal of Research in Interprofessional Practice and Education

Vol. 3.2

August, 2013

\section{Journal of Research in Interprofessional Practice and Education}

5. O’Connor, A.M., Drake, E.R, Wells, G.A., Tugwell, P., Laupacis, A., \& Elmslie, T. (2003). A survey of the decision-making needs of Canadians faced with complex health decisions. Health Expectations, 6(2), 97-109.

6. Hinojosa, J., Sproat, C.T., Mankhetwit S., \& Anderson, J. (2002, September-October). Shifts in parent-therapist partnerships: Twelve years of change. American Journal of Occupational Therapy, 56(5), 556-563.

7. Brown, D., White, J., \& Leibbrandt, L. (2006). Collaborative partnerships for nursing faculties and health service providers: What can nursing learn from business literature? Journal of Nursing Management, 14, 170-179.

8. Schroder, C., Medves, J., Paterson, M., Byrnes, V., Chapman, C., O’Riordan, A., Pichora, D., \& Kelly, C. (2011). Development and pilot testing of the collaborative practice assessment tool (CPAT). Journal of Interprofessional Care 25(3), 189-195.

9. Crossan, M., Lane, H.W., White, R.E. (1999). An organizational learning framework: From intuition to institution. The Academy of Management Review, 24(3), 522-537.

10. Orchard, C.A., Curran, V., \& Kabene, S. (2005). Creating a culture for interdisciplinary collaborative professional practice. Medical Education Online, 10(11), 1-13.

11. Reeves S. (2010). Ideas for the development of the interprofessional field. [Editorial]. Journal of Interprofessional Care, 24(3), 217-219.

12. Senge, P.M., Keleiner, A., Roberts, C., Ross, R.G., \& Smith, B. (1999). The dance of change: The challenges of sustaining momentum in learning organizations. New York, NY: Doubleday.

13. Bally, J.M.G. (2007). The role of nursing leadership in creating a mentoring culture in acute care environments. Nursing Economics, 25(3), 143-149.

14. Romanow, R.J. (2002). The commission on the future of health care in Canada. In Romanow Commission Report, pp. 1-355. Ottawa, ON: Health Canada.

15. Tellis-Nayak, V. (2007, January). A person-centered workplace: The foundation for person-centered caregiving in long-term care. Journal of American Medicine Directory Association, 8(1), 46-54.

16. Applebaum, S.H., Mitraud, A., Gailleur, J-F., Iacovella, M., Gerbasi, R., \& Ivanova, V. (2008). The impact of organizational change, structure and leadership on employee turnover: A case study. Journal of Business Case Studies, 4, 21-37.

17. Gilbert, J.H.V., Yan, J., Hoffman, S.J. (2010). A WHO report: Framework for Action on Interprofessional Education and Collaboratvie Practice. Journal of Allied Health, 39(3 pt 2), 196-197.

18. Brander, R.A., Paterson, M., \& Chan, Y. (2013). Fostering change in organizational culture using a critical ethnographic approach. The Qualitative Report. (Accepted for publication, August, 2012).

19. Creswell, J.W. (2003). Research design: Qualitative, quantitative, and mixed methods approaches, 2nd editon. Thousand Oaks: Sage Publications.

20. Patton, M.Q. (2002). Qualitative research and evaluation methods, 3rd edition. Thousand Oaks: Sage Publications.

21. LeCompte, M.D., \& Schensul, J.J. (1999). Analyzing and interpreting ethnographic data. Walnut Creek, CA: AltaMira.

22. Higgs, J., Titchen, A., Horsfall, D., \& Armstrong, H.B. (Eds.). (2007). Being critical and creative in qualitative research. Sydney: Hampden Press.

23. Higgs, J., Horsfall, D., \& Grace, S. (Eds.). (2009). Writing qualitative research on practice. Rotterdam: Sense Publishers.

24. Speziale, H.S., \& Carpenter, D.R. (2007). Qualitative research in nursing: Advancing the humanistic imperative. Philadelphia: Lippincott Williams \& Wilkins.

25. LeCompte, M.D., \& Schensul, J.J. (1999). Designing and conducting ethnographic research. Walnut Creek: Atamira Press.

26. Ontario Telemedicine Network. (2012). ONT News. URL:'http://otn.ca/ílJune 5, 2013].

27. Bart, C.K., \& Hupfer, M. (2004). Mission statements in Canadian hospitals. Journal of Health Organization and Management, 18(2), 92-110.

28. Youngblood, M.D. (1997). Leadership at the edge of chaos: From control to creativity. Strategy and Leadership, 25(5), 8-14.

29. Registered Nursing Association of Ontario (RNAO). (2006). Nursing best practice guideline slient centred care_supplement (rey.supplement, cited 2010 Mar 18, 2010). URL:'http://www.rnao.cai' 'Lbpg/guidelines/client-centred-cared[June 8,2013].

30. Ford, P.E.A., Rolfe, S., \& Kirkpatrick, H. (2011). A journey to patient-centred care in Ontario, Canada: Implementation of a best practice guideline. Clinical Nurse Specialist 25(4), 198-206. 
25

Using a Common Vision of "Partners in Care"

Arnold Brander, Paterson, \& Chan
31. Brown, J., \& Duguid, P. (1991). Organizational learning and communities-of-practice: Toward a unified view of working, learning, and innovation. Organization Science, 2(1), 40-57.

32. Goh, S.C. (2002). Managing effective knowledge transfer: An integrative framework and some practice implications. Journal of Knowledge Management, 6(1), 23-30.

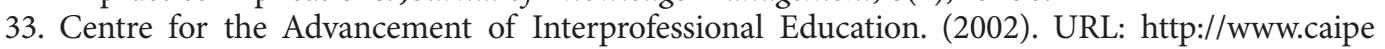

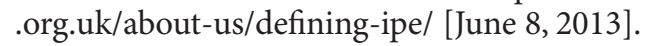

34. Pearce, C.L., \& Congre, J.A. (2003). Shared leadership: Reframing the hows and whys of leadership. Thousand Oaks, CA: Sage Publications.

35. Crossan, M., Vera, D., \& Nanjad, L. (2008). Transcendent leadership: Strategic leadership in dynamic environments. The Leadership Quarterly, 19, 569-81.

36. Kernick, D., \& Mitchell, A. (2010). Working with lay people in health service research: A model of co-evolution based on complexity theory. Journal of Interprofessional Care, 24(1), 31-40.

37. The Canadian Interprofessional Health Collaborative. (2010). A national interprofessional competency framework. Vancouver, BC: Canadian Interprofessional Health of Canada.

38. World Health Organization. (2010). Framework for action on interprofessional education \& collaborative practice. World Health Organization Press, Geneva.

39. Denis, J.L., Davies, H.T.O., Ferlie, E., \& Fitzgerald, L. (2011). Assessing initiatives to transform healthcare systems: Lessons for the Canadian healthcare system. Ottawa, ON: Canadian Health Services Research Foundation. 